\title{
Imagens do gênero nas disputas pelo poder na América Latina
}

Images of The Genre in Power Disputes in Latin America

\author{
Joyce Miranda Leão Martins' (iD) 0000-0002-6215-8706 \\ 'Pontifícia Universidade Católica de São Paulo, Programa de Pós-Graduação em \\ Ciência Política, São Paulo, SP, Brasil. 01223-010 - esecretaria@fespsp.org.br
}

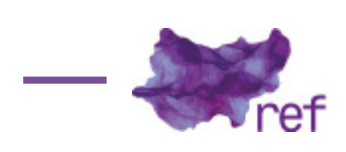

PANKE, Luciana.

Campañas electorales para mujeres: retos y tendencias.

Puebla/México: Piso 15 Editores, 2015.

O livro Campañas electorales para mujeres: retos y tendencias, de Luciana Panke, parte da constatação de que "la política es un universo masculino" (PANKE, 2015, p. 3). Com foco na América Latina, a autora busca esclarecer tal entendimento com dados sobre a participação política de mulheres; a análise de cotas nos partidos e parlamentos; e elabora questionamentos sobre os papéis sociais destinados a mulheres e homens. Sua pesquisa, fruto de pós-doutorado realizado na Universidad Autónoma Metropolitana (UAM), abrange, além de entrevistas com políticas, políticos e consultores/as de marketing, a comparação entre imagens públicas de mulheres candidatas em campanhas eleitorais no México e no Brasil, sua terra natal.

Afirmando que "vivimos en una estructura social donde la dominación de un sexo sobre el otro no solamente es vista como normal, como la única opción de funcionamiento" (PANKE, 2015, p. 4), Panke retoma o pensamento dos gregos para falar de misoginia - o "repúdio ao feminino". Não é preciso ir tão distante nessa volta ao passado. Mas, refletir acerca dos obstáculos impostos às mulheres na política torna fundamental um regresso ao apogeu da modernidade e ao seu imaginário político. O período foi fundado com a emergência histórica do indivíduo e sobre as bases da diferença sexual (tendo em vista que só os homens ganhavam o estatuto de ser pensante, livre e igual).

Tendo os homens atingido a idade da razão, perceberam que a origem do poder político não poderia ser satisfatoriamente explicada a partir de algum poder pátrio ou divino. Assim, apenas o consentimento de todos os sujeitos poderia esclarecer e tornar legítima a sociedade política. As mulheres, segundo eles, estavam na infância do pensamento e, incapazes de evoluir, deveriam ficar restritas ao espaço doméstico e de fora dos contratos sociais - fundadores das crenças generalizadas de nossas contemporâneas sociedades ocidentais e da América Latina.

Ali, na modernidade, também se encontrava, entretanto, os primórdios do feminismo. Mary Wollstonecraft, em obra escrita no ano de 1792, foi das primeiras a introduzir a crítica à distinção entre público e privado (que marcaria a tradição política do feminismo no Ocidente) e a afirmar que "o direito divino dos maridos, tal qual o direito divino dos reis, pode, é de esperar nesta época iluminista, ser questionado sem perigo" (Mary WOLLSTONECRAFT, 2016, p. 64). A provocação de Wollstonecraft antecipava em dois séculos a percepção de Carole Pateman de que a morte do patriarcado não passava de ficção. Pois, não tendo um sentido apenas paternal, significou, na 
modernidade, que as mulheres estavam subordinadas aos homens como fraternidade. Afirma Pateman (1993, p. 18) que "O contrato original é feito depois da derrota política do pai e cria o patriarcado fraternal moderno". Wollsonecraft (2016) também antecipou em séculos a discussão sobre gênero, conceito que passou a ser usado pelas feministas anglo-saxãs (Joan SCOTT, 2012) para diferenciar condicionamentos biológicos dos sociais: ela negava a existência de virtudes próprias de determinado sexo e falava em distinções inaturais para explicar a posição de homens e mulheres na sociedade do seu tempo.

As estruturas simbólicas que organizam a sociedade a partir do gênero só permitiram que as mulheres começassem a conquistar a cidadania e a exigir seus espaços na categoria de indivíduo na aurora do século XX. O direito de votar e de serem votadas veio depois de muitos debates teóricos e manifestações pelas ruas das cidades. Chegavam atrasadas, correndo sem fôlego, em um percurso que havia sido percorrido tranquilamente por aqueles que há muito tempo haviam se autoproclamado donos do poder. Como percebe Panke: "al género masculino le está concedido este espacio y a los demás se les resta intentar abrir caminos" (PANKE, 2015, p. 12).

Nesse sentido, é de relevância incontornável trabalhos que problematizem a trajetória das mulheres em direção aos espaços de poder. É uma questão de qualidade da representação e da democracia. Como a própria Panke questiona: "¿Cómo es posible que la mitad de la población todavía sea considerada 'minoría' en la toma de las decisiones?" (PANKE, 2015, p. 3). Em um espaço 100\% masculino, resolvemos entrar sem pedir licença, reivindicando percentual mínimo de cotas para o gênero; tendo como ideal, a paridade, $50 \%$. Vitória conquistada, em 2017 , pelas políticas argentinas posicionadas em distintos lugares do horizonte político.

Nossa contínua exclusão das esferas de poder, entretanto, evidencia que os mecanismos formais não são suficientes para garantir e tornar efetiva a participação política das mulheres, institucionalmente falando. Um insight simples como as cotas - que Panke analisa em seu livro não resolveu a desigualdade de gênero porque os problemas são complexos, localizados e multicausais: envolvem a engenharia de sistemas e legislações eleitorais nacionais, apoio partidário eficaz, financiamento de campanhas e, com peso bastante forte, questões culturais. Janet Camilo, política da República Dominicana, ao ser entrevistada por Panke (2015), conta que, em seu país, as mulheres seguem apoiando homens porque "no hay costumbre de apoyar a mujeres" (PANKE, 2015, p. 22). Um exemplo claro de como as estruturas subjetivas condicionam e efetivam os comportamentos sociais.

Fruto da produção simbólica da modernidade (que teve no colonialismo sua contraface), a cultura discriminatória de gênero colabora para a compreensão das imagens observadas por Panke nas campanhas de mulheres na América Latina: a dona de casa, a guerreira, a mãe, a responsável, a sensível, a submissa e a trabalhadora. Sendo a mãe um referencial quase sacralizado na América Latina, a mulher sai do lar não por interesse político, não para afirmar sua perspectiva diante das pautas parlamentares, mas por um amor maior que a fizera abdicar do seu espaço tradicional. Sem questionar a separação entre o público e o privado, mas, ao contrário, tomandoo como a origem de seus desejos de atuar em nome da população, as candidatas vão na contramão dos feminismos. A persistente separação entre o público e o privado é, aliás, o que Pateman (1993) percebe como origem das causas das desigualdades entre homens e mulheres, tendo em vista que o lugar social dos homens, o trabalho na esfera pública, é dotado de maior reconhecimento e status.

Vale destacar que a pesquisa de Panke foi realizada antes da eleição presidencial brasileira de 2014 e, talvez por isso, não tenha abordado também uma importante imagem política, mobilizada naquela eleição: a herdeira (Joyce MARTINS, Cristina ALTMANN, 2018). Em comum com as imagens percebidas por Panke, a herdeira promove o ingresso subordinado das mulheres na política e ainda de modo mais evidente: ela está ali como extensão de um legado, representando alguém que por algum impedimento não pôde ser o "verdadeiro" postulante ao cargo. Sua função, tal como a da mãe e a da dona de casa, talvez fosse estar dentro do âmbito privado, do qual também se afasta devido a um imperativo. Nesse sentido, o imaginário da modernidade, que se reproduz e se atualiza contemporaneamente, mostra-se resistente nos lugares mais insuspeitos: onde a mulher foi capaz de contornar obstáculos para garantir presença.

Provavelmente, as campanhas não são assim só porque estamos falando de sociedades machistas. Os partidos políticos são um dos responsáveis pela persistência da desigualdade de gênero nos espaços do poder, ao dar menor espaço para as mulheres e ao legitimar propagandas eleitorais que atualizam e reproduzem estereótipos, definidos por Virginia García Beaudoux (2014, p. 49) como: "creencias generalizadas y socialmente compartidas acerca de los atributos de las personas que conforman un determinado grupo social".

As políticas que conversaram com Panke apontam as dificuldades que precisam enfrentar dentro de suas legendas: não fazem parte das mesas diretoras; não recebem financiamento de campanha do mesmo modo que os homens; sofrem assédio moral e sexual. Essa cultura, reproduzida pelas siglas partidárias, desestimula novos imaginários do poder. 
Como já dito, os caminhos são tortuosos. A defesa da participação política das mulheres nos espaços decisórios é uma causa antiga, mas seria melhor, falando especificamente de campanhas eleitorais, que elas entrassem nas disputas, enfrentando não apenas seus oponentes, mas também a dominação masculina, com seus constrangimentos simbólicos e materiais. Comportamento que passaria pela aceitação, por parte das sociedades latino-americanas, de novas imagens do gênero no poder. Para empoderar as mulheres, Panke afirma, "es necesario desarrollar una serie de iniciativas que van desde cambios en los roles de género enseñados en las familias y en las escuelas primarias, [...] así como la promoción de talleres y entrenamiento para mujeres interesadas en ingresar en la políica" (PANKE, 2015, p. 19). Ao final do seu livro, Panke elenca uma série de dicas e estratégias para aquelas que queiram adentrar no mundo da política institucional.

A estrada é longa, mas nem tudo são desventuras e desesperanças. A entrada das mulheres nos espaços de poder traz a exigência de negociações e institui novas relações entre os gêneros (Joana PEDRO, 2000), capazes, acreditamos, de sacudir as estruturas simbólicas que sustentam a organização do mundo social baseada na distinção de gênero.

\section{Referências}

GARCÍA BEAUDOUX, Virginia. "Influencia de la televisión en la creación de estereotipos de género y en la percepción social del liderazgo femenino. La importancia de la táctica de reencuadre para el cambio social". Ciencia política, v. 9, n. 18, p. 47-66, 2014. Disponível em: https:// revistas.unal.edu.co/index.php/cienciapol/article/view/52305/52048. Acesso em: 17/1 1/2018.

MARTINS, Joyce Miranda Leão; ALTMANN, Cristina. "Os usos do gênero na campanha presidencial de 2014: mulheres na propaganda eleitoral brasileira". Revista Teoria \& Pesquisa, v. 27, n. 1, p. 4870, 2018.

PANKE, Luciana. Campañas electorales para mujeres: retos y tendencias. 1.ed. Puebla/México: Piso 15 Editores, 2015.

PATEMAN, Carole. O contrato sexual. Trad. de Marta Avancini. Rio de Janeiro: Paz e Terra, 1993.

PEDRO, Joana Maria. "As mulheres e a separação das esferas". Diálogos, v. 4, n. 1, p. 33-39, 2000. Disponível em: http://www.periodicos.uem.br/ojs/index.php/Dialogos/article/view/37600. Acesso em: $17 / 11 / 2018$.

SCOTT, Joan. "Os usos e abusos do gênero". Projeto História, n. 45, p. 327-351, dez 2012.

WOLLSTONECRAFT, Mary. Reivindicação dos direitos da mulher. Trad. de Ivania Pocinho Motta. São Paulo: Boitempo, 2016.

Joyce Miranda Leão Martins (joycesnitram@yahoo.com.br) fez pós-doutorado na Pontifícia Universidade Católica de São Paulo (PUC/SP), com bolsa FAPESP. Doutora em Ciência Política pela Universidade Federal do Rio Grande do Sul (UFRGS). Realizou estágio de doutorado na Universidad Complutense de Madrid (UCM). Bacharela em Ciências Sociais pela Universidade Federal do Ceará (UFC) e mestra em Sociologia pela mesma instituição. Pesquisadora vinculada ao Núcleo de Estudos em Arte, Mídia e Política (Neamp) da PUC/SP. Desenvolve estudos relacionados à construção de imagens públicas da política, horário eleitoral, estratégias discursivas do poder, gênero e teoria política.

COMO CITAR ESSE ARTIGO DE ACORDO COM AS NORMAS DA REVISTA

MARTINS, Joyce Miranda Leão. "Imagens do gênero nas disputas pelo poder na América Latina". Revista Estudos Feministas, Florianópolis, v. 27, n. 3, e58742, 2019.

CONTRIBUIÇÃO DE AUTORIA

Não se aplica.

FINANCIAMENTO

Fapesp - processo: 17/02644-3, vinculado ao projeto temático lideranças políticas: características e questões institucionais, processo: 12/50987-3. 


\section{CONSENTIMENTO DE USO DE IMAGEM}

Não se aplica.

APROVAÇÃO DE COMITÊ DE ÉTICA EM PESQUISA

Não se aplica.

\section{CONFLITO DE INTERESSES}

Não se aplica.

\section{LICENÇA DE USO}

Este artigo está licenciado sob a Licença Creative Commons CC-BY International. Com essa licença você pode compartilhar, adaptar, criar para qualquer fim, desde que atribua a autoria da obra.

\section{HISTÓRICO}

\section{Recebido em 20/08/2018}

Revisões requeridas em 24/1 1/2018

Aprovado em 21/04/2019

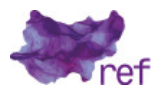

